\title{
Association between wheeze and selected air pollution sources in an air pollution priority area in South Africa: a cross-sectional study
}

Joyce Shirinde ${ }^{1,2^{*}+}$, Janine Wichmann ${ }^{2+}$ and Kuku Voyi ${ }^{2+}$

\begin{abstract}
Background: An association between wheeze (a symptom of asthma) and environmental tobacco smoke (ETS), types of fuel used for residential heating or cooking and the frequency of trucks passing near homes, has been reported mainly in developed countries. Little is known about the strength of such associations in developing countries. This study was conducted in residential areas situated in Ekurhuleni Metropolitan Municipality, namely Tembisa and Kempton Park, which form part of the Highveld region, a priority area in terms of air pollution in South Africa.
\end{abstract}

Methods: From 3764 eligible school children, aged between 13 and 14 years, from 16 selected high schools in the study area, 3468 completed a modified questionnaire based on the International Study of Asthma and Allergies in Childhood (ISAAC). Data were analysed using multiple logistic regression models.

Results: The results are based on data from 3424 children. In the adjusted models, exposure to ETS at school was associated with wheeze ever (OR 1.22 95\% Cl: 1.03 - 1.45) and current wheeze (OR 1.33 95\% Cl: 1.08 - 1.64). When gas was most frequently used for residential heating the likelihood of wheeze ever increased by $47 \%$ (OR 1.47 95\% Cl: 1.15 - 1.88). Trucks passing near homes for almost the whole day during weekdays, increased the likelihood of wheeze ever (OR 1.32 95\% Cl: 1.01 - 1.73), current wheeze (OR 1.61 95\% Cl: 1.15 - 2.24) and current severe wheeze (OR 2.22 95\% Cl: 1.28 - 3.77). When data were stratified according to residential area, for children living in Tembisa, ETS exposure at home was associated with current wheeze (OR $1.3695 \% \mathrm{Cl}: 1.06-1.77)$; gas most frequently used for residential heating was associated with wheeze ever (OR 1.68 95\% Cl: $1.23-2.28$ ) and current wheeze (OR 1.61 95\% Cl: 1.08 - 2.39); paraffin most frequently used for residential heating was associated with current severe wheeze (OR 1.85 95\% Cl: $1.04-3.28)$.

Conclusion: It was concluded that children living in one of the air pollution priority areas of South Africa, have an increased risk of wheezing due to exposure to both indoor and outdoor air pollution sources.

Keywords: Wheeze, Asthma, Environmental tobacco smoke, Heating fuel, Cooking fuel, Traffic, Air pollution, South Africa, Industrial

\footnotetext{
* Correspondence: shirindej@tut.ac.za

${ }^{\dagger}$ Equal contributors

'Department of Environmental Health, Tshwane University of Technology, Private Bag X680, Pretoria 0001, South Africa

${ }^{2}$ School of Health Systems and Public Health, Health Sciences Faculty, University of Pretoria, P.O. Box 667, Pretoria 0001, South Africa
} 


\section{Background}

Environmental air pollution is a major global health risk factor. Studies conducted in various parts of the world have reported a wide range of adverse effects of ambient air pollution $[1,2]$. There is growing evidence linking respiratory symptoms in children to air pollution [1]. Children are more vulnerable as their immune system and lungs are not fully developed when air pollution exposure begins [3]. Personal exposure of children to air pollutants occurs mainly in three microenvironments, home, school and during transport, which Ashmore and Dimitroulopoulou discuss in detail [3]. Environmental tobacco smoke (ETS), combustion of fuels for residential cooking/heating and the frequency of trucks passing near homes have all been associated with respiratory diseases in children $[4,5]$.

Tobacco smoke is one of the most common indoor air pollutants. As early as the seventies, literature has periodically reviewed ETS, or passive smoking and health [5]. Although parental smoking is the most common source of exposure to ETS, children are also exposed in areas such as schools, restaurants and public transport vehicles [6].

The burning of biomass fuel (BMF) (wood, charcoal, dung, crop residues and other raw plant material), for cooking, heating or both, remain the most widespread and important source of exposure to air pollution [7]. About 2.4 billion people worldwide live in households where BMF is the primary fuel for cooking, heating or both, with more than $90 \%$ being in rural areas [7]. Other sources of indoor air pollution are stoves and heaters using gas or paraffin fuel. Gas space heaters have nitrogen dioxide $\left(\mathrm{NO}_{2}\right)$ emission rates similar to gas stoves and are often used for long periods of time in living and sleeping areas. This may result in $\mathrm{NO}_{2}$ concentrations four or more times higher than gas stoves used for cooking [8]. Pollutants emitted during paraffin (kerosene) combustion include carbon dioxide, sulphur dioxide, $\mathrm{NO}_{2}$, particulate matter, formaldehyde, various hydrocarbons and volatile organic compounds [9].

Exhaust emissions are an important source of trafficrelated air pollution. According to the latest World Health Organization (WHO) technical report, there is sufficient evidence linking vehicle emissions to the health of people living in close proximity to roads $[1,10]$. Many epidemiological studies in developed countries have investigated the association between asthma symptoms (e.g. wheeze) and traffic-related pollution [11-14]. Little is known about the strength of such associations in developing countries, such as South Africa.

Our study was conducted in Tembisa (a township with formal and informal housing) and Kempton Park (a suburb with formal housing), situated in the northern region of Ekurhuleni Metropolitan Municipality (EMM), in the eastern region of Gauteng Province, South Africa. This is the first study using the International Study of Asthma and Allergies in Childhood (ISAAC) methodology, conducted in Gauteng Province, a heavily industrialised urban area. Two previous South African studies applied the ISAAC methodology; one in Cape Town, Western Cape Province, an industrial coastal city; and the second in Polokwane, Limpopo Province $[15,16]$. It was justifiable to conduct this study in EMM as the meteorology and air are different from that of Cape Town and Polokwane. Ekurhuleni Metropolitan Municipality covers approximately $1923 \mathrm{~km}^{2}$ and forms part of the Highveld region, which was the second region in South Africa to be declared an air pollution priority area by the Minister of Environmental Affairs in 2007, in terms of the National Environmental Management: Air Quality Act, 2004 (Act No. 39 of 2004) [17].

According to a baseline air quality assessment report for the EMM in 2004, vehicular exhaust emissions (both petrol and diesel) were identified as significantly contributing to air pollution [18]. Other sources of air pollution included: residential fuel burning (particularly coal), industrial and commercial fuel burning (coal-fired boilers in close proximity to residential areas), OR Tambo International Airport (contributing a small fraction of low level, concentrated $\mathrm{NO}_{2}$ ) and large industries associated with various stack, vent and fugitive emissions [18].

The aim of our study was to investigate the association of wheeze, a symptom of asthma with indoor and outdoor air pollution sources, specifically ETS, the types of fuel most frequently used for residential cooking or heating, transportation to school and the frequency of trucks passing near homes in urban areas of Tembisa and Kempton Park.

\section{Methods}

\section{Study area}

Tembisa is the second largest township in Gauteng Province, with both formal and informal housing and mainly inhabited by people belonging to Black/African ethnic groups. Under apartheid, South Africans were categorised into one of four socially defined race or ethnic groups: African/Black (descent primarily from one of a number of Black language groups in Southern Africa), Coloured (general grouping, including a mixture of Black, Malay, European and indigenous Khoisan ancestry), White (mainly European ancestry) and Asian (Indian sub-continent ancestry). Race is still linked to both past and present access to resources, socioeconomic status and educational status. Kempton Park is a suburban area surrounded by industry and arterial roads connecting Gauteng Province. OR Tambo International Airport, which is Africa's busiest airport, is also located here. Kempton Park residents are predominantly 
White and it is only in recent years, after the 1994 democratic elections, that some mostly middle income Black/African families moved into the area. According to the Statistics South Africa (2011), most households in Tembisa had an annual household income of between R19 601- R38 200 in contrast Kempton Park where most households had an income of between R153 801 - R307 600 [19].

\section{Study design, population and sample selection}

A cross-sectional epidemiological study was conducted between February and June 2012. The ISAAC Phase I protocol was followed [20]. A list of all schools (primary and secondary) in EMM was provided by the Gauteng Department of Education and 16 high schools were randomly selected from this list. Each school was contacted and requested to participate in the study. Following the approval of the study by the principal and governing body in each school, all eligible children between the ages of 13 and 14 years and in Grade 8 were requested to participate. Each school was requested to make available a copy of class lists. An appointment was scheduled with the school to deliver the consent forms for the children two weeks prior to the study and they were requested to return them within three days.

The study population consisted of 3764, children based on the numbers given by each school prior to data collection. Data were collected using the English version of ISAAC written and video questionnaires. Data on the latter, which were believed to be more specific for asthma, were not included in the analysis, as the questionnaire could not be completed in some schools, due to logistical problems such as unavailability of electricity, challenges of moving audio-visual equipment from class to class, or lack of a suitable venue where the children could watch the video.

\section{Health outcomes}

In this study, we estimated the following health outcomes, on the basis of positive answers from the written questionnaire: wheeze ever ["Have you ever had wheezing or whistling in the chest at any time in the past?"], current wheeze ["Have you had wheezing or whistling in the chest in the past 12 months?"]. Current severe wheeze was defined as those who, according to the written questionnaire, responded positively to all four questions:

1) "How many attacks of wheeze have you had in the past 12 months?". For this question, the children could select one of the following four options: a) none, b) 1-3 attacks, c) 4-12 attacks or d) more than 12 attacks in the past 12 months. Included in the definition of severe wheeze were those who had 4-12 attacks, or more than 12 attacks, in the past 12 months.
2) "In the past 12 months how often on average has your sleep been disturbed due to wheezing?". For this question, the children could select one of the following three options: a) Never woken up with wheezing, b) one night per week, c) one or more nights per week. Included in the definition of severe wheeze were those who indicated one night per week or one or more nights per week.

3) "In the past 12 months, has wheezing ever been severe enough to limit your speech to only one or two words at a time between breaths?". For this question, the option was yes or no.

4) "In the past 12 months, has your chest ever sounded wheezy during or after exercise?". For this question, the option was yes or no.

\section{Air pollution sources}

Air pollution sources included: ETS exposure at home in the past 30 days (yes/no), ETS exposure at school in the past 30 days (yes/no), tobacco smoking by participant (yes/no), mother/father smoking tobacco (yes/no), any other person smoking tobacco at home other than parents (yes/no). The children were asked to select the most frequently used source of energy at home, therefore had to select only one type of energy source: for cooking (electricity/gas/paraffin/wood/coal) and for heating (electricity/gas/paraffin/wood/coal). Other air pollution sources were: transportation mode to school (walking, informal taxi/bus, car, combination car/taxi or train), and frequency of trucks passing near residences (never/seldom/frequently through the day/almost all day).

\section{Confounders}

Potential confounding variables included the following: sex (male/female), type of residential area (township: Tembisa or suburb: Kempton Park), period lived in the residential area ( $<6$ months/ 6 to 12 months/ 1 to 2 years/ $\geq 3$ years), type of house (brick/mud/corrugated iron/combination), availability of running water at home (yes/no), vigorous physical activity (never/occasionally/ 1-2 times per week/ $\geq 3$ times per week), pets (cat and/or $\operatorname{dog}$ ) in and around the home (yes/no), hours watching television per day $(<1 \mathrm{hr} / 1 \mathrm{hr}$ but $<3 \mathrm{hrs} / 3 \mathrm{hrs}$ but $<5 \mathrm{hrs} / \geq 5 \mathrm{hrs}$ ), use of paracetamol in the past 12 months (never/once per year/once per month), mother's education level (primary school/secondary/tertiary education), average travel time from home to hospital (15 minutes' walk or 5 minute drive/1 hour walk or 15 minutes' drive/ $\geq$ an hour's walk or $\geq 30$ minute drive), regular dietary intake of 15 food items e.g. meat, pasta, rice (never or occasionally/once or twice per week/three or more times a week). 


\section{Data management and statistical analysis}

The data were entered into a database set up in EpiInfo V3.5.3. Stata Version 12 was applied to the data analysis. The prevalence of the health outcomes and proportion of air pollution and confounding variables, were calculated by dividing the number of participants who responded affirmatively to a particular question by the number of questionnaires completed. Observations marked as "do not know", "not stated" or "other responses" were set as missing. This resulted in each question having a slightly different sample size.

Crude and adjusted odds ratios (OR) and 95\% confidence intervals $(\mathrm{CI})$ were calculated to estimate the likelihood of health outcomes given the presence of an air pollution source and confounding variables. Univariate and multiple logistic regression analysis (LRA) were applied. All missing values were automatically excluded from the LRA. Air pollution and confounding variables that had $p$ values estimated as less than 0.02 in the univariate LRA, were included in the multiple LRA. Only $p$ values less than 0.05 in the multiple LRA, were considered statistically significant. The data were further stratified according to area of residence, Tembisa (township) or Kempton Park (suburb) to determine if the observed associations for the overall study population applied to the two areas separately. Interaction between vigorous physical activity and outdoor air pollution (i.e. truck traffic) were investigated to determine if there was any effect modification on current wheeze. During vigorous exercise more pollutants tend to be deposited in the lungs, resulting in increased bronchial hypersensitivity.

\section{Ethical considerations}

This study was approved by the Ethics and Research Committee of the Faculty of Health Sciences, University of Pretoria (S121\2011). The Gauteng Department of Education, Ekurhuleni North District, the school principals and governing bodies were approached and gave their consent and cooperation for the study. Parents of participants were sent a letter explaining the details and nature of the study and were given the option of withdrawing their child from the study at any time should they wish to do so. Data collectors and capturers were instructed to keep all information confidential.

\section{Results}

Of the 3764 children, 3468 completed the modified ISAAC questionnaire at the schools (92\% response rate). The study focused only on those children who were present at the time of fieldwork and so 296 learners did not participate. The teachers gave an assurance that most of the children were present. School attendance was high during the study, thus bias that may have been introduced by non-response, was assumed to be relatively low.
Forty-four questionnaires were excluded during data capture, due to incomplete information. A total of 3424 questionnaires were finally included in the data analysis.

The frequencies and percentages for general characteristics and living conditions are summarised in Table 1 . The prevalence of having had wheeze in the past, current wheeze and current severe wheeze during the past 12 months was $32 \%, 18 \%$ and $12 \%$, respectively. Girls accounted for $52 \%$ of participants and the mean age was 13 years. The majority of the children lived in Tembisa (67\%). More than three quarters had lived in the same area for longer than three years (76\%). Just over half of the children were born in the area where they were currently living. Nearly one third of the children reported occasionally or never engaging in any vigorous physical activity (29\%). The majority exercised once or twice per week (42\%), while the remaining third engaged in vigorous physical activity three or more times a week.

Just over half of the children walked to school (51\%), while the rest used other modes of transport (cars, taxi, buses and train). A small percentage of children reported gas most frequently (5\%) and paraffin most frequently used (5\%) for cooking at home, while the majority most frequently used electricity (88\%). Twelve percent most frequently used gas for heating, $18 \%$ most frequently used paraffin, $7 \%$ most frequently used open fires (wood and coal) the remaining $52 \%$ most frequently used electricity. Ten percent of the children had a mother or female guardian who was a smoker, $27 \%$ a father or male guardian who was a smoker, or lived with someone other than their parents, who was a smoker (44\%). Forty two percent of children reported having been exposed to ETS at home and 34\% at school.

Other variables not included in Table 1 were measured as potential confounders. The majority $(86 \%)$ of the children lived in formal housing structures and fewer than $20 \%$ lived in houses without running water. More than a quarter of the pupils spent, on average, more than five hours per day watching television (36\%). Half of the children reported that the average travel time from home to a hospital was more than an hour's walk or 30 minutes' drive. More than one third of the children reported taking paracetamol at least once per year, while $44 \%$ reported taking it at least once per month during the past year. A small percentage $(8 \%)$ reported having a cat at home in the past year, while $14 \%$ had had a cat in the past. A third of the children had a dog at home during the past year, while $43 \%$ had had one sometime in the past.

Tables 2, 3 and 4 summarise the results of multiple LRA for the overall study population. ETS exposure at school increased the likelihood of wheeze ever (OR 1.22 95\% CI: $1.03-1.45$ ) and current wheeze (OR 1.33 95\% 
Table 1 Demographic characteristics, health outcomes and sources of air pollution exposure of the study participants $(n=3424)$

\begin{tabular}{|c|c|c|c|c|c|}
\hline Variable & Total & Percentage & Residential heating fuel type most & & \\
\hline Sex of child & & & frequently used & & \\
\hline Female & 1790 & 52.3 & Electricity & 2041 & 59.6 \\
\hline Male & 1634 & 47.7 & Gas & 426 & 12.4 \\
\hline Missing & - & - & Paraffin & 631 & 18.4 \\
\hline Wheeze ever & & & Open fires (wood, coal) & 270 & 7.9 \\
\hline Yes & 1081 & 31.6 & Missing & 56 & 1.6 \\
\hline No & 2343 & 68.4 & $\begin{array}{l}\text { Frequency of trucks passing near } \\
\text { homes on weekdays }\end{array}$ & & \\
\hline Missing & - & - & Never & 563 & 16.4 \\
\hline yes & 619 & 182 & Seldom & 1033 & 30.2 \\
\hline No & 2789 & 81.4 & Frequently through the day & 580 & 16.9 \\
\hline Missing & 16 & 0.47 & Almost all day & 1212 & 35.4 \\
\hline Current severe wheeze & & & Missing & 36 & 1.1 \\
\hline Yes & 417 & 12.1 & $\begin{array}{l}\text { ETS exposure at school in the } \\
\text { past } 30 \text { days }\end{array}$ & & \\
\hline No & 3007 & 87.8 & No & 1452 & 42.4 \\
\hline Missing & - & - & Yes & 1177 & 34.4 \\
\hline Residential area & & & Missing & 795 & 23.2 \\
\hline Kempton Park & 1117 & 32.6 & ETS exposure at residence in the & & \\
\hline Tembisa & 2301 & 67.2 & past 30 days & & \\
\hline Missing & 6 & 0.2 & No & 1460 & 42.6 \\
\hline Period lived in the residential area & & & Yes & 1452 & 42.4 \\
\hline$<6$ months & 253 & 7.4 & Missing & 512 & 15 \\
\hline $6-12$ months & 216 & 6.3 & $\begin{array}{l}\text { Active tobacco smoker in the past } \\
12 \text { months }\end{array}$ & & \\
\hline $1-2$ years & 346 & 10.1 & Yes & 100 & 29 \\
\hline$\geq 3$ years & 2609 & 76.2 & No & 3274 & 2.9 \\
\hline Missing & - & - & Missing & $32 / 4$ & 95.6 \\
\hline Mode of transport to schools & & & Missing & 50 & 1.5 \\
\hline
\end{tabular}

Table 1 Demographic characteristics, health outcomes and sources of air pollution exposure of the study participants ( $n=3424)$ (Continued)

Residential heating fuel type most quently used

Frequency of trucks passing near es on weekdays

ETS exposure at school in the past 30 days
50.5

Residential cooking fuel type most frequently used

$\begin{array}{lll}\text { Electricity } & 2995 & 87.5 \\ \text { Gas } & 179 & 5.2 \\ \text { Paraffin } & 200 & 5.8 \\ \text { Open fires (wood, coal) } & 30 & 0.9 \\ \text { Missing } & 20 & 0.6\end{array}$

CI: $1.08-1.64)$. Gas most frequently used for heating was associated with wheeze ever (OR 1.47 95\% CI: 1.15 1.88). Trucks passing near homes almost the whole day during weekdays increased the likelihood of wheeze ever (OR 1.32 95\% CI: 1.01 - 1.73), current wheeze (OR 1.61 95\% CI: $1.15-2.24$ ) and current severe wheeze (OR 2.22 95\% CI: $1.28-3.77)$.

Significant confounders were gender, type of residential area and engaging in vigorous physical activity. Boys were found to be less likely to have wheeze ever (OR 0.69 95\% CI: $0.58-0.82$ ) and current wheeze (OR 0.65 95\% CI: $0.53-$ $0.81)$. Living in Tembisa significantly decreased the likelihood of wheeze ever (OR 0.62 95\% CI: $0.51-0.76$ ) and current wheeze (OR 0.61 95\% CI: $0.49-0.77$ ). Vigorous physical activity "once or twice a week" and "three or more times a week" increased the likelihood of wheeze ever (OR 1.66 95\% CI: $1.34-2.07$ ) and (OR 1.39 95\% CI: 1.10 - 1.77), and current wheeze (OR 1.59 95\% CI: 1.22 - 2.07) and (OR 
Table 2 Prevalence of wheeze ever amongst the participants (Tembisa and Kempton Park combined) along with crude and adjusted odd ratios

\begin{tabular}{|c|c|c|c|c|c|c|}
\hline Variable & Total $^{\mathrm{a}}$ & $\begin{array}{l}\text { Prevalence } \\
(\%)\end{array}$ & Crude OR $(95 \%$ Cl) & $p$ & $\underset{c}{\text { Adjusted OR }(95 \% \mathrm{Cl})^{\mathrm{b}}}$ & $p$ \\
\hline \multicolumn{7}{|l|}{ Sex of child } \\
\hline Female & 1790 & 35.1 & 1 & & 1 & \\
\hline Male & 1634 & 27.7 & $0.7(0.61-0.81)$ & 0.000 & $0.69(0.58-0.82)$ & 0.000 \\
\hline \multicolumn{7}{|l|}{ Residential area } \\
\hline Kempton Park & 1117 & 37.1 & 1 & & 1 & \\
\hline Tembisa & 2301 & 28.9 & $0.69(0.59-0.80)$ & 0.000 & $0.62(0.51-0.76)$ & 0.000 \\
\hline \multicolumn{7}{|c|}{ Vigorous physical activity per week } \\
\hline Never or occasionally & 984 & 23.3 & 1 & & 1 & \\
\hline Once or twice per week & 1417 & 35.9 & $1.84(1.53-2.22)$ & 0.000 & $1.66(1.34-2.07)$ & 0.000 \\
\hline Three or more times a week & 983 & 33.8 & $1.68(1.37-2.05)$ & 0.000 & $1.39(1.10-1.77)$ & 0.006 \\
\hline \multicolumn{7}{|c|}{ Residential heating fuel type most frequently used } \\
\hline Electricity & 2041 & 30.0 & 1 & & 1 & \\
\hline Gas & 426 & 39.2 & $1.50(1.21-1.86)$ & 0.000 & $1.47(1.15-1.88)$ & 0.002 \\
\hline Paraffin & 631 & 31.8 & $1.06(0.88-1.29)$ & 0.508 & $0.06(0.83-1.37)$ & 0.597 \\
\hline Open fires (wood, coal) & 270 & 33.3 & $1.16(0.89-1.52)$ & 0.261 & $1.16(0.83-1.62)$ & 0.360 \\
\hline \multicolumn{7}{|c|}{$\begin{array}{l}\text { Frequency of trucks passing near homes on } \\
\text { weekdays }\end{array}$} \\
\hline Never & 563 & 28.2 & 1 & & 1 & \\
\hline Seldom & 1033 & 33.3 & $1.26(1.01-1.58)$ & 0.038 & $1.10(0.84-1.44)$ & 0.351 \\
\hline Frequently through the day & 580 & 28.4 & $1.01(0.78-1.30)$ & 0.938 & $0.89(0.65-1.23)$ & 0.539 \\
\hline Almost all day & 1212 & 33.5 & $1.27(1.02-1.59)$ & 0.020 & $1.32(1.01-1.73)$ & 0.035 \\
\hline \multicolumn{7}{|c|}{ ETS exposure at school in the past 30 days } \\
\hline No & 1452 & 29.0 & 1 & & 1 & \\
\hline Yes & 1177 & 34.5 & $1.20(0.08-1.50)$ & 0.004 & $1.22(1.03-1.45)$ & 0.020 \\
\hline
\end{tabular}

${ }^{\mathrm{a}}$ Totals for each risk factor are different due to difference in missing value.

balues that are statistically significant at less than 0.02 for the crude OR and less than 0.05 for the adjusted OR are in bold font.

'Model adjusted for all the variables in this table.

1.32 95\% CI: $0.99-1.77)$ respectively. Physical activity "three or more times a week" increased the likelihood of current severe wheeze (OR 1.76 95\% CI: $1.09-2.84$ ). In a sensitivity analysis, we investigated interaction between vigorous physical activity and truck traffic on current wheeze. We did not observe any interaction.

When the data were stratified by location of schools in Tembisa and Kempton Park (summarised in Tables 5 and 6), ETS exposure at home was associated with current wheeze for children residing in Tembisa (OR 1.36 95\% CI: 1.06 - 1.77). In Tembisa gas most frequently used for residential heating was associated with wheeze ever, (OR 1.68 95\% CI: $1.23-2.28$ ) and current wheeze (OR 1.61 95\% CI: 1.08 - 2.39). Paraffin most frequently for residential heating was associated with current severe wheeze (OR 1.85 95\% CI: 1.04 - 3.28). In Kempton Park, gas most frequently used for residential cooking was associated with wheeze ever (OR 1.65 95\% CI: $1.04-2.61$ ). Trucks passing near homes almost the whole day during weekdays increased the likelihood of current wheeze for those residing in Kempton Park (OR 2.13 95\% CI: $1.24-3.65)$ and the likelihood of current severe wheeze for those in Tembisa (OR 3.34 95\% CI: 1.70 6.55).

Transportation mode to school, active smoking by study participant, mother/father smoking, or any other person smoking at home, were not significantly associated with wheeze by the univariate LRA.

\section{Discussion}

The study investigated the association between wheeze, and indoor and outdoor air pollution sources, in an urban industrialised area in South Africa. When Tembisa and Kempton Park were considered together, detrimental associations were observed between wheeze ever/current wheeze/severe wheeze in 13-14 year old children, and exposure to ETS at school, residential gas heating and truck traffic near homes.

A recent report from centres in different countries that participated in the ISAAC Phase III, reported a 
Table 3 Prevalence of current wheeze amongst the participants (Tembisa and Kempton Park combined) along with crude and adjusted odd ratios

\begin{tabular}{|c|c|c|c|c|c|c|}
\hline Variable & Total $^{\mathrm{a}}$ & Prevalence (\%) & Crude OR $(95 \% \mathrm{Cl})^{\mathrm{b}}$ & $p$ & Adjusted OR $(95 \% \mathrm{Cl})^{\mathrm{b}, \mathrm{c}}$ & $p$ \\
\hline \multicolumn{7}{|l|}{ Sex of child } \\
\hline Female & 1779 & 20.8 & 1 & & 1 & \\
\hline Male & 1629 & 15.3 & $0.69(0.57-0.82)$ & 0.000 & $0.65(0.53-0.81)$ & 0.002 \\
\hline \multicolumn{7}{|l|}{ Residential area } \\
\hline Kempton Park & 1114 & 21.9 & 1 & & 1 & \\
\hline Tembisa & 2290 & 16.3 & $0.69(0.58-8.83)$ & 0.000 & $0.61(0.49-0.77)$ & 0.000 \\
\hline \multicolumn{7}{|c|}{ Vigorous physical activity per week } \\
\hline Never & 980 & 13.6 & 1 & & 1 & \\
\hline Once or twice per week & 1409 & 20.7 & $1.66(1.33-2.08)$ & 0.000 & $1.59(1.22-2.07)$ & 0.002 \\
\hline Three or more time a week & 979 & 19.4 & $1.53(1.20-1.95)$ & 0.001 & $1.32(0.99-1.77)$ & 0.210 \\
\hline \multicolumn{7}{|l|}{ Use of paracetamol } \\
\hline Never & 716 & 13.0 & 1 & & 1 & \\
\hline At least once a year & 1104 & 15.5 & $1.22(0.93-1.61)$ & & $0.91(0.65-1.26)$ & 0.586 \\
\hline At least once per month & 1523 & 22.5 & $1.93(1.51-2.48)$ & 0.000 & $1.55(1.14-2.09)$ & 0.004 \\
\hline \multicolumn{7}{|c|}{$\begin{array}{l}\text { Frequency of trucks passing near } \\
\text { homes on weekdays }\end{array}$} \\
\hline Never & 560 & 14.5 & 1 & & 1 & \\
\hline Seldom & 1029 & 19.0 & $1.38(1.04-1.83)$ & 0.025 & $1.24(0.89-1.74)$ & 0.151 \\
\hline Frequently through the day & 580 & 16.4 & $1.15(0.83-1.59)$ & 0.371 & $0.97(0.65-1.44)$ & 0.874 \\
\hline Almost the whole day & 1203 & 20.3 & $1.50(1.14-1.97)$ & 0.004 & $1.61(1.15-2.24)$ & 0.006 \\
\hline \multicolumn{7}{|c|}{$\begin{array}{l}\text { Having a cat in and around the } \\
\text { house in the past } 12 \text { months }\end{array}$} \\
\hline No & 3129 & 17.9 & 1 & & 1 & \\
\hline Yes & 264 & 21.6 & $1.55(1.23-1.95)$ & 0.000 & $1.49(1.13-1.98)$ & 0.005 \\
\hline \multicolumn{7}{|c|}{$\begin{array}{l}\text { ETS exposure at school in the } \\
\text { past } 30 \text { days }\end{array}$} \\
\hline No & 1446 & 16.2 & 1 & & 1 & \\
\hline Yes & 1169 & 20.2 & $1.3(0.06-1.59)$ & 0.009 & $1.33(1.08-1.64)$ & 0.020 \\
\hline
\end{tabular}

${ }^{\text {a }}$ Totals for each risk factor are different due to difference in missing values.

balues that are statistically significant at less than 0.02 for the crude OR and less than 0.05 for the adjusted OR are in bold font.

${ }^{c}$ Model adjusted for all the variables in this table.

global average of $14 \%$ for current wheeze for 13-14 year old children [16]. Current wheeze ranged from 5\% in Northern and Eastern Europe to $22 \%$ in Oceania. Thirty-five centres (15\%) had a prevalence of current wheeze $\geq 20 \%$, located mostly in English language countries and Latin America. Twenty two centres (9\%) had a prevalence of $<5 \%$, mostly in the Indian subcontinent, Asia-Pacific and eastern Mediterranean [21]. The prevalence of current wheeze reported in this study, was similar to that reported in English language countries and Latin America. Although these countries may have a high prevalence of asthma, the disease appears to be less often recognised and more severe in Africa, the Indian subcontinent and the Eastern Mediterranean [21]. The prevalence of current wheeze and current severe wheeze for the Polokwane ISAAC study was $11 \%$ and $6 \%$, respectively
[16], while the prevalence of current wheeze was $20 \%$ in the Cape Town study [15].

Exposure to ETS at school was positively associated with wheeze ever and current wheeze for the overall study population. Health effects associated with exposure to ETS have long been established [22-26]. A more recent literature review by Burke et al. reported that exposure to passive smoking increases the incidence of wheeze and asthma in children and young people by at least 20\% [27]. Current legislation and policies on tobacco smoking should be strengthened to reduce smoking in public places such as schools. In the stratified analysis, ETS exposure at home was significant for current wheeze in Tembisa. Significantly more ETS exposure at home was observed for Tembisa than Kempton Park (chi square test $<0.0001$ ). It is plausible that exposure to tobacco smoke might be associated with lower 
Table 4 Prevalence of current severe wheeze amongst the participants (Tembisa and Kempton Park combined) along with crude and adjusted odd ratios

\begin{tabular}{|c|c|c|c|c|c|c|}
\hline Variable & Total $^{\mathrm{a}}$ & Prevalence (\%) & Crude OR $(95 \% \mathrm{Cl})^{\mathrm{b}}$ & $p$ & Adjusted OR $(95 \% \mathrm{Cl})^{\mathrm{b}, \mathrm{c}}$ & $p$ \\
\hline \multicolumn{7}{|l|}{ Pasta consumption } \\
\hline Never or occasionally & 136 & 72.1 & 1 & & 1 & \\
\hline Once or twice per week & 319 & 67.1 & $0.81(0.52-1.26))$ & 0.359 & $0.78(0.49-1.24)$ & 0.301 \\
\hline Three or more times per week & 122 & 59.0 & $0.55(0.33-0.93)$ & 0.023 & $0.54(0.31-0.93)$ & 0.027 \\
\hline \multicolumn{7}{|c|}{ Vigorous physical activity per week } \\
\hline Never & 133 & 59.4 & 1 & & 1 & \\
\hline Once or twice per week & 292 & 68.5 & $1.48(0.97-2.27)$ & 0.068 & $1.46(0.93-2.30)$ & 0.099 \\
\hline Three or more time a week & 190 & 72.6 & $1.81(1.13-2.90)$ & 0.013 & $1.76(1.09-2.84)$ & 0.030 \\
\hline \multicolumn{7}{|c|}{$\begin{array}{l}\text { Frequency of trucks passing near } \\
\text { homes on weekdays }\end{array}$} \\
\hline Never & 81 & 56.8 & 1 & & 1 & \\
\hline Seldom & 195 & 62.1 & $1.24(0.73-2.10)$ & 0.416 & $1.16(0.68-1.98)$ & 0.598 \\
\hline Frequently through the day & 95 & 67.4 & $1.57(0.84-2.90)$ & 0.150 & $1.44(0.77-2.69)$ & 0.333 \\
\hline Almost the whole day & 244 & 75.4 & $2.33(1.37-3.95)$ & 0.002 & $2.22(1.28-3.77)$ & 0.006 \\
\hline \multicolumn{7}{|l|}{$\begin{array}{l}\text { Having a cat in and around the } \\
\text { house in the past } 12 \text { months }\end{array}$} \\
\hline No & 499 & 65.4 & 1 & & 1 & \\
\hline Yes & 117 & 76.1 & $1.68(1.06-2.67)$ & 0.024 & $1.68(1.03-2.73)$ & 0.035 \\
\hline
\end{tabular}

${ }^{a}$ Totals for each risk factor are different due to difference in missing values.

${ }^{b}$ Values that are statistically significant at less than 0.02 for the crude OR and less than 0.05 for the adjusted OR are in bold font.

${ }^{c}$ Model adjusted for all the variables in this table.

socio-economic status (SES) [28-31]. Eight percent of the children in Tembisa lived in informal housing structures (corrugated iron) compared to $0.7 \%$ in Kempton Park (chi square test $\mathrm{p}<0.0001)$. However, residual confounding due to other unmeasured SES factors may still be present.

Gas most frequently used for heating (overall study population) was only associated with wheeze ever. However, when the data were stratified by Tembisa and Kempton Park, it was interesting to observe that for children residing in Tembisa, gas most frequently used for heating at home was associated wheeze ever and current wheeze, whilst for those in Kempton Park gas most frequently used for cooking was associated with wheeze ever. Although current wheeze and severe wheeze (more specific outcomes than wheeze ever) were less common in Tembisa than Kempton Park, when gas or paraffin were most frequently used for residential heating the likelihood of these health outcomes increased in Tembisa, but not in Kempton Park. A reason for this may due to the fact that gas and paraffin are significantly more frequently used for residential heating in Tembisa than Kempton Park (chi square test $\mathrm{p}<0.0001$ ). Also, significantly more polluting fuels that were frequently used for cooking occurred in Tembisa than in Kempton Park (chi square test $\mathrm{p}<0.0001$ ).

Even though there is an increase in the electrification of both rural and urban areas, many South African households still rely on alternative sources of energy such as biomass fuel, gas and paraffin. According to the 2011 South African Census report, 26\% of 51 million people still relied on alternative energy for cooking and $41.2 \%$ for heating. Eight and a half percent of the South African population still relied on paraffin for cooking and the same percentage applied for heating. This was due to rising costs of electricity. Gas heaters have been identified as a common indoor source of nitrogen dioxide $\left(\mathrm{NO}_{2}\right)$ and particulate matter [8]. Heating devices can be used for many hours per day reflecting higher exposure, which over time can have $\mathrm{cu}-$ mulative health effects [32]. A study conducted by Muller et al., to assess the health risks of paraffin usage in an informal settlement in Durban, South Africa, showed a significant health risk resulting from paraffin usage in homes [9]. Venn et.al also found an association between wheeze and the use of paraffin in the home, in a study conducted in Ethiopia [33]. Ruiz et al. investigated the impact of gas and paraffin space heaters on indoor air quality in Chile and found an impact only for paraffin heaters [34].

For the overall study population, trucks passing near homes almost the whole day during weekdays, were identified as another air pollution source that had a detrimental association with wheeze ever, and an even stronger link to current wheeze and severe wheeze. It is well established that living close to a road with heavy traffic is associated with wheeze and other respiratory symptoms [35-37]. Brunekreef et al. analysed data from 
Table 5 Prevalence of wheeze ever, current wheeze and severe wheeze amongst the participants from Tembisa along with crude and adjusted odd ratios

\begin{tabular}{|c|c|c|c|c|c|c|}
\hline & Total $^{\mathrm{a}}$ & Prevalence (\%) & Crude OR $(95 \% \mathrm{Cl})^{\mathrm{b}}$ & $p$ & Adjusted OR(95\% Cl) & $p$ \\
\hline \multicolumn{7}{|l|}{ Wheeze ever ${ }^{c}$} \\
\hline \multicolumn{7}{|c|}{ Vigorous physical activity per week } \\
\hline Never or occasionally & 696 & 20.8 & 1 & & 1 & 1 \\
\hline Once or twice per week & 975 & 40.1 & $1.84(1.47-2.31)$ & 0.000 & $1.82(1.44-2.28)$ & 0.000 \\
\hline Three or more times a week & 605 & 32.4 & $1.82(1.41-2.33)$ & 0.000 & $1.75(1.36-2.26)$ & 0.000 \\
\hline \multicolumn{7}{|c|}{ Residential heating fuel type most frequently used } \\
\hline Electricity & 1233 & 26.7 & 1 & & 1 & \\
\hline Gas & 214 & 39.2 & $1.77(1.31-2.40)$ & 0.000 & $1.68(1.23-2.28)$ & 0.001 \\
\hline Paraffin & 607 & 30.6 & $1.21(0.98-1.50)$ & 0.075 & $1.16(0.94-1.45)$ & 0.159 \\
\hline Open fires (wood, coal) & 207 & 20.0 & $1.06(0.77-1.48)$ & 0.688 & $1.01(0.73-1.41)$ & 0.912 \\
\hline \multicolumn{7}{|l|}{ Current wheeze $e^{\mathrm{d}}$} \\
\hline \multicolumn{7}{|c|}{ Residential heating fuel type most frequently used } \\
\hline Electricity & 1225 & 15.2 & 1 & & 1 & \\
\hline Gas & 212 & 22.2 & $1.59(1.11-2.27)$ & 0.011 & $1.61(1.08-2.39)$ & 0.018 \\
\hline Paraffin & 606 & 17.5 & $1.18(0.91-1.53)$ & 0.205 & $0.81(0.58-1.13)$ & 0.222 \\
\hline Open fires, wood, coal & 207 & 31.0 & $0.83(0.54-1.29)$ & 0.424 & $0.63(0.38-1.05)$ & 0.077 \\
\hline \multicolumn{7}{|c|}{ ETS exposure at home in the past 30 days } \\
\hline No & 914 & 14.1 & 1 & & 1 & \\
\hline Yes & 998 & 18.7 & $1.40(1.09-1.79)$ & 0.007 & $1.36(1.06-1.77)$ & 0.017 \\
\hline \multicolumn{7}{|c|}{ Vigorous physical activity per week } \\
\hline Never or occasionally & 692 & 11.6 & 1 & & 1 & \\
\hline Once or twice per week & 970 & 18.8 & $1.76(1.33-2,34)$ & 0.000 & $1.81(1.31-2.50)$ & 0.000 \\
\hline Three or more times a week & 603 & 18.2 & $1.70(1.25-2.33)$ & 0.001 & $1.61(1.12-2.30)$ & 0.009 \\
\hline \multicolumn{7}{|l|}{ Severe wheeze $e^{\mathrm{e}}$} \\
\hline \multicolumn{7}{|c|}{ Residential heating fuel type most frequently used } \\
\hline Electricity & 186 & 66.1 & 1 & & 1 & \\
\hline Gas & 47 & 78.2 & $1.89(0.88-4.05)$ & 0.100 & $1.95(0.89-4.27)$ & 0.093 \\
\hline Paraffin & 106 & 79.2 & $1.95(1.11-3.42)$ & 0.019 & $1.85(1.04-3.28)$ & 0.034 \\
\hline Open fires, wood, coal & 27 & 77.7 & $1.79(0.68-4.66)$ & 0.232 & $1.76(0.66-4.68)$ & 0.257 \\
\hline \multicolumn{7}{|c|}{ Frequency of trucks passing near homes on weekdays } \\
\hline Never & 52 & 55.7 & & & 1 & \\
\hline Seldom & 80 & 90.2 & $1.64(0.84-3.59)$ & 0.131 & $1.90(0.90-4.09)$ & 0.088 \\
\hline Frequently through the day & 61 & 70.1 & $1.89(0.87-4.11)$ & 0.107 & $2.02(0.91-4.47)$ & 0.080 \\
\hline Almost all day & 180 & 80.55 & $3.28(1.69-6.35)$ & 0.000 & $3.34(1.70-6.55)$ & 0.000 \\
\hline
\end{tabular}

110 ISAAC centres and found a positive relationship between symptoms of current wheeze in 13 to 14 year olds and self-reported truck traffic near homes [38]. A similar OR was observed for this study. When the data were stratified by area of residence, trucks passing near homes increased the likelihood of current wheeze for those in
Kempton Park. The association was much stronger when compared to the unstratified analysis. The association between truck traffic and current severe wheeze for Tembisa was stronger than that of the overall sample. It appears that traffic-related air pollution is an important risk factor for children in both Tembisa and Kempton Park. 
Table 6 Prevalence of wheeze ever and current wheeze amongst the participants from Kempton Park along with crude and adjusted odd ratios

\begin{tabular}{|c|c|c|c|c|c|c|}
\hline & Total $^{\mathrm{a}}$ & Prevalence (\%) & Crude OR $(95 \% \mathrm{Cl})^{\mathrm{b}}$ & $p$ & AdjustedOR $(95 \% \mathrm{CI})^{\mathrm{b}}$ & $p$ \\
\hline \multicolumn{7}{|l|}{ Wheeze ever } \\
\hline \multicolumn{7}{|c|}{ Residential cooking fuel type most frequently used } \\
\hline Electricity & 1003 & 35.1 & 1 & & 1 & \\
\hline Gas & 92 & 48.9 & $1.73(1.12-2.65)$ & 0.012 & $1.65(1.04-2.61)$ & 0.030 \\
\hline Paraffin & 8 & 50.0 & $1.80(0.44-7.27)$ & 0.404 & $1.59(0.37-6.70)$ & 0.526 \\
\hline Open fires, wood, coal & 10 & 50.0 & $1.80(0.52-6.29)$ & 0.351 & $1.83(0.47-7.07)$ & 0.375 \\
\hline \multicolumn{7}{|c|}{ Residential heating fuel type most frequently used } \\
\hline Electricity & 803 & 35.1 & 1 & & 1 & \\
\hline Gas & 211 & 39.3 & $1.28(0.87-1.63)$ & 0.256 & $1.06(0.76-1.48)$ & 0.696 \\
\hline Paraffin & 24 & 50.0 & $1.84(0.81-4.16)$ & 0.139 & $1.61(0.69-3.73)$ & 0.267 \\
\hline Open fires, wood, coal & 63 & 50.8 & $1.90(1.13-3.19)$ & 0.014 & $1.75(1.02-3.09)$ & 0.040 \\
\hline \multicolumn{7}{|c|}{ Vigorous physical activity per week } \\
\hline Never or occasionally & 228 & 29.1 & 1 & & & \\
\hline Once or twice per week & 437 & 43.2 & $1.85(1.34-2.54)$ & 0.000 & $1.80(1.30-2.49)$ & 0.000 \\
\hline Three or more times a week & 377 & 36.0 & $1.37(0.95-1.90)$ & 0.061 & $1.30(0.93-1.83)$ & 0.119 \\
\hline \multicolumn{7}{|l|}{ Current wheeze $e^{\mathrm{d}}$} \\
\hline \multicolumn{7}{|c|}{ Frequency of trucks passing near homes on weekdays } \\
\hline Never & 186 & 15.6 & 1 & & 1 & \\
\hline Seldom & 526 & 26.8 & $1.49(0.95-2.34)$ & 0.077 & $1.46(0.90-2.37)$ & 0.123 \\
\hline Frequently through the day & 164 & 20.7 & $1.41(0.81-2.44)$ & 0.213 & $1.34(0.74-2.44)$ & 0.322 \\
\hline Almost all day & 226 & 28.3 & $2.13(1.30-3.49)$ & 0.002 & $2.13(1.24-3.65)$ & 0.006 \\
\hline \multicolumn{7}{|c|}{ Vigorous physical activity per week } \\
\hline Never or occasionally & 288 & 18.4 & 1 & & & \\
\hline Once or twice per week & 435 & 20.0 & $1.48(1.03-2.14)$ & 0.024 & $1.35(0.90-2.20)$ & 0.145 \\
\hline Three or more times a week & 376 & 21.2 & $1.19(0.81-1.18)$ & 0.360 & $1.04(0.67-1.60)$ & 0.856 \\
\hline \multicolumn{7}{|c|}{ ETS exposure at school in the past 30 days } \\
\hline No & 507 & 19.7 & 1 & & & \\
\hline Yes & 445 & 24.4 & $1.74(1.123-2.69)$ & 0.013 & $1.34(0.98-1.60)$ & 0.066 \\
\hline
\end{tabular}

${ }^{\text {a }}$ Totals for each risk factor are different due to difference in missing values.

${ }^{b}$ Values that are statistically significant at less than 0.02 for the crude OR and less than 0.05 for the adjusted OR are in bold font.

${ }^{\mathrm{c}}$ Model adjusted for: Residential cooking/heating fuel types and vigorous physical activity.

${ }^{\mathrm{d}}$ Model adjusted for: Frequency of trucks passing near homes, vigorous physical activity and exposure to tobacco smoke at school.

Although the majority of studies have been conducted in developed countries, a few studies from Africa have also found an association between wheeze and frequency of trucks passing near homes $[39,40]$. With an increase in industrialisation and number of vehicles, developing countries are facing the same challenges as those in developed countries, i.e. experiencing high levels of pollution, especially in urban areas where the majority of people are concentrated. In recent years South Africa has been developing rapidly and the number of cars on South African roads has increased tremendously, the number of vehicles (licensed only) in Gauteng province alone, in February 2013, was over 4.2 million [41]. As the number of vehicles continues to increase annually, traffic levels will increase on South
African roads, leading to increased levels of traffic related pollution.

In a sensitivity analysis, interaction (effect modification) between vigorous physical activity and truck traffic on current wheeze was investigated. We did not observe any effect modification. None of the other ISAAC studies investigated effect modification between these two factors.

Limitations should be taken into account in the interpretation of the results. The ISAAC methodology has many inherent limitations: Firstly, the study had a cross-sectional epidemiological design. Secondly, the results were based on self-reported answers from a questionnaire. Self-reported answers can introduce recall bias, which may lead to misclassification of disease and 
exposure status. Children who had recently experienced episodes of wheezing, might have exaggerated their exposures, which may have led to overestimation, while underestimation could have occurred for those who did not recall exactly when wheezing occurred. Thirdly, the study found an association between air pollution sources and wheeze ever. The question on wheeze ever, does not mention attacks of wheezing in order to identify children with persistent symptoms characterised as episodes of attacks [42]. Many studies focus on current wheeze. Responses to questions about self-reported wheezing during the previous 12 months were shown to have good specificity for both bronchial hypersensitivity and a diagnosis of asthma in both children and adults [43]. Fourth, the exclusion of the video questionnaire data is disappointing, because it is believed to be more specific for asthma.

Fifthly, no quantitative air pollution exposure assessment was conducted during the study; the data were not analysed for mixed fuel types for residential heating or cooking, frequency and duration of fuel use at home and the number of cigarettes smoked were not included. Sixth, the frequency of trucks passing near homes on weekdays, may have been misclassified, as on weekdays, children are at school. Lastly, although the study area was done in an air pollution priority area, on the basis of multiple sources of air pollution; only proximity to truck traffic was investigated as an ambient (outdoor source) exposure variable. We did not include any other questions e.g. on distance of industries from residential areas. More research should be conducted in the area to investigate other outdoor air pollution sources.

The strength of our study is mainly the use of a validated ISAAC questionnaire regarding symptoms of wheeze. The ISAAC core questions have been used extensively in international studies of childhood asthma. Furthermore the participation rate was very high, which eliminated the risk of selection bias. This is the first ISAAC study conducted in an urban industrialised area in South Africa and the first to report an association between wheeze and traffic-related pollution. The study will contribute to existing literature about the prevalence of asthma symptoms amongst South African children, particularly of the age group 13 to 14 years. The baseline data will serve as a benchmark for future epidemiological studies.

\section{Conclusion}

It was concluded that wheeze in children was associated with ETS, types of fuel used for residential cooking or heating and the frequency with which trucks passed close to homes in Ekurhuleni. Tobacco use was more strongly associated with wheeze in children exposed to smoking at school, than at home. It is advised that smoking exposure at schools needs to be better controlled. There appeared to be a difference between air pollution levels and wheeze, in children living in urban areas of Tembisa, in contrast to Kempton Park, which may be associated with different socioeconomic levels. It was also interesting that trucks passing close to homes in residential areas investigated were associated with more severe symptoms. This needs further investigation.

\section{Abbreviations}

Cl: Confidence intervals; BMF: Biomass fuel; EMM: Ekurhuleni Metropolitan

Municipality; ETS: Environmental tobacco smoke; OR: Odds ratio; ISAAC: International Study of Asthma and Allergies in Childhood; $\mathrm{NO}_{2}$ : Nitrogen dioxide; LRA: Logistic regression analysis.

\section{Competing interest}

The authors declare that they have no competing interests.

\section{Acknowledgements}

The authors would like to thank all the children who completed the questionnaires, the parents, school principals and the Gauteng Department of Education for giving permission to conduct the study, the students who conducted the interviews, the data capturers and Cornelius Nuttey for his assistance during the data processing stages.

The authors would like to thank the University of Pretoria, Tshwane University of Technology, Medical Research Council and the National Research Foundation for funding the study for academic research purposes.

\section{Authors' contributions}

JS participated in the design of the study, acquisition of data, statistical analysis and interpretation of the results and draft of the manuscript. JW participated in the design of the study, statistical analysis, interpretation of results and critically revised the manuscript. KV participated in the design of the study, statistical analysis, interpretation of results and critically revised the manuscript. All authors have read and approved the final manuscript.

Received: 15 July 2013 Accepted: 28 April 2014

Published: 6 May 2014

\section{References}

1. World Health Organisation: Review of evidance on health aspects of air pollution- REVIHAAP Project. ; 2013. Technical Report.

2. Cohen AJ, Anderson HR, Ostra B, Pandey KD, Krzyzanowski M, Kunzli N, Gutschmidt K, Pope A, Romieu I, Samet JM, Smith K: The global burden of disease due to air outdoor air pollution. J Toxicol Environ Health A 2005, 68:1-7.

3. Ashmore MR, Dimitroulopoulou C: Personal exposure of children to air pollution. Atmos Environ 2009, 43:128-141.

4. Laumbach RJ, Kipen HM: Respiratory health effects of air pollution: update on biomass smoke and traffic pollution. J Allergy Clin Immunol 2012, 129:3-11.

5. Chan-Yeung M, Dimich-Ward H: Respiratory health effects of exposure to environmetal tobacco smoke. Respirology 2003, 8:131-139.

6. Cheraghi M, Salvi S: Environmetal tobacco smoke (ETS) and respiratory health in children. Eur J Pediatr 2009, 168:897-905.

7. Smith KR, Mehta S, Maeusezahl-Feuz M: Indoor air pollution from solid fuel use. In Comarative quantification of health risks: global and regional burden of disease attributable to selected major risk factors. Edited by Ezzatti M, Lopez AD, Rodgers A, Murray CJL. Geneva (Swittzerland): World Health Organisation; 2004:1435.

8. Belanger $\mathrm{K}$, Triche EW: Indoor conmbustion and asthma. Immunol Allergy Clin North Am 2008, 28:507

9. Muller E, Diab RD, Binedell M, Hounsome R: Health risk assessment of kerosene usage in an informal settlement in Durban. S Afr Atmos Environ 2003, 37:2015-2022.

10. Jerrett M, Shankardass K, Berhane K, Gauderman WJ, Kunzli N, Avol E, Gilliland F, Lurmann F, Molitor JN, Molitor TJ, Thomas DC, Peters J, McConnell R: Traffic- related air pollution and asthma onset in children: 
a prospective cohort study with individual exposure measurement. Environ Health Perspect 2008, 116:1433-1438.

11. Kim JJ, Huen K, Adams S, Smorodinsky S, Hoats A, Malig B, Lipsett M, Ostro B: Residential traffic and children's respiratory health. Environ Health Perspect 2008, 116:1274-1279.

12. Spira-Cohen A, Chen LC, Kendall M, Sheesley R, Thurston GD: Personal exposures to traffic-related particle pollution among children with asthma in the South Bronx, NY. J Expo Sci Environ Epidemiol 2010, 20:446-456.

13. Perez L, Lurmann F, Wilson J, Pastor M, Brandt JS, Kunzli N, McConnell R: Near-roadway pollution and childhood asthma: implications for developing "win-win' compact urban development and clean vehicle strategies. Environ Health Perspect 2012, 120:1619-1626.

14. Migliore E, Berti G, Galassi C, Pearce N, Forastiere F, Calabrese R, Armenio L, Biggeri A, Bisanti L, Bugiani M, Cadum E, Chellini E, Dell'Orco V, Giannella G, Sestini P, Corbo G, Pistelli R, Viegi F, Ciccone G, SIDRIA-2 Collaborative Group: Respiratory symptoms in children living near busy roads and their relationship to vehicular traffic: results of an Italian multicenter study (SIDRIA 2). Environ Health 2009, 8:27.

15. Ehrlic RI, Du Toit D, Jordaan E, Volkmink JA, Wanburg EG, Zwarenstein M: Prevalence and reliability of asthma symptoms in primary school children in Cape Town. Int J Epidemiol 1995, 24:1138-1145.

16. Wichmann J, Wolvaardt JE, Maritz C, Voyi KW: Household conditions, eczema symptoms and rhinitis symptoms: relationship with wheeze and severe wheeze in children living in Polokwane area, South Africa. Matern Child Health J 2009, 13:107-118,

17. Africa S: National Environmental Management: Air Quality Act, 2004 (Act No. 39 of 2004). Pretoria: Government Printers; 2004.

18. Scorgie $Y$, Fischer $T$, Watson R: Air quality management plan for the Ekurhuleni Metropolitan Municipality. 2005, [http://www.ekurhuleni.gov.za]

19. Statistics South Africa. [http://beta2.statssa.gov.za]

20. Asher MI, Keil U, Anderson HR, Beasley R, Crane J, Martinez F, Mitchell EA, Pearce N, Sibbald B, Stewart AW, Strachan D, Weiland SK, Williams HC: International study of Asthma and allergies in childhood (ISAAC): rationale and methods. Eur Respir J 1995, 8:483-491.

21. The ISAAC Phase Three Study Group, Lai CKW, Beasley R, Crane J, Foliaki S, Shah J, Weiland S: Global variation in the prevalence and severity of asthma symptoms: Phase Three of the International Study of Asthma and allergies in childhood (ISAAC). Thorax 2009, 64:476-483.

22. Ashley JM, Robertta F: Reducing childrens exposure to environmental tobacco smoke in homes: issues and strategies. Tob Control 1998, 7:61-65.

23. Lee $W$, Galant S: Effects of maternal smoking during pregnacy and environmetal tobacco smoke on asthma and wheezing in children. Paediatr 2002, 110:445-446.

24. Jaakkola JJK, Gissler M: Maternal smoking in pregnancy, foetal development, and childhood asthma. Am J Public Health 2004, 94:136-140.

25. Cook DG, Strachan DP: Parental smoking and the prevalence of respiratory symptoms and asthma in school age children. Thorax 1997, 52:1081-1094

26. Cook DG, Strachan DP: Summary of effect of parental smoking on the respiratory health of children and implications for research. Thorax 1999, 54:357-366

27. Burke H, Leonardi-Bee J, Hashim A, Pine-Abata H, Chen Y, Cook DG, Britton JR, McKeever TM: Prenatal and passive smoke exposure and incidence of asthma and wheeze: systematic review and meta-analysis. Pediatrics 2012, 129:735-744.

28. Turrell G, Hewitt BA, Miller SA: The influence of neighbourhood disadvantage on smoking cessation and its contribution to inequalities. Drug Alcohol Rev 2012, 31:645-652.

29. Barnett JR: Does place of residence matter? Contextual effects of smoking in Christchurch. N Z Med J 2000, 113:433-435.

30. Yi O, Kwon HJ, Kim D, Kim H, Ha M, Hong SJ, Hong YC, Leem JH, Sakong J, Lee CG, Kim SY, Kang D: Association between environmental tobacco smoke exposure of children and parental socioeconomic status: a crosssectional study in Korea. Nicotine Tob Res 2012, 14:607-615.

31. Linetzky B, Mejia R, Ferrante D, De Maio FG, Diez Roux AV: Socioeconomic status and tobacco consumption among adolescents: a multilevel analysis of Argentina's global youth tobacco survey. Nicotine Tob Res 2012, 14:1092-1099.
32. De Bilderling G, Chauhan AJ, Jeffs JAR, Withers N, Johnston SL, Holgate ST, Clough JB: Gas cooking and smoking habits and the brisk of childhood and adolescent wheeze. Am J Epidemiol 2005, 162:513-522.

33. Venn AJ, Yemaneberhan H, Bekele Z, Lewis SA, Parry E, Britton J: Increased risk of allergy associated with the use of kerosene fuel in the home. Am J Respir Crit Care Med 2001, 164:1660-1664.

34. Ruiz PA, Toro C, Caceres J, Lopez G, Oyola P, Koutrakis P: Effect of gas and kerosene space heaters on indoor air quality: a study in homes of Santiago, Chile. J Air Waste Manage Assoc 2010, 60:98-107.

35. Middleton N, Yiallouros P, Nicolaou N, Kleanthous S, Pipis S, Zeniou M, Demokritou $P$, Koutrakis $P$ : Residential exposure to motor vehicles emmisions and the risk of wheezing among 7-8 year old school children: a city wide cross -sectional study in Nicosia, Cyprus. Environ Health 2010, 9:28.

36. Andersson M, Modig L, Hedman L, Forsberg B, Ronmark E: Heavy vehicle traffic is related to wheeze among schoolchildren: a population-based study in an area with low traffic flows. Environ Health 2011, 10:91.

37. Brugge D, Durant JL, Rioux C: Near-highway pollutants in motor vehicle exhaust: A review of epidemiologic evidence of cardiac pulmonary health risks. Environ Health 2007, 6:23.

38. Brunekreef B, Stewart AW, Anderson HR, Lai CKW, Strachan DP, Pearce N, The ISAAC Phase 3 Study Group: Self-Reported Truck Traffic on the street of residence and symptoms of asthma and allergic disease: A global relationship in ISAAC Phase 3. Environ Health Perspect 2009, 117:1791-1798.

39. Mustapha BA, Blangiardo M, Briggs DJ, Hansell AL: Traffic air pollution and other risk factors for respiratory illnes in school children in the Niger- Delta region of Nigeria. Environ Health Perspect 2011, 119:1478-1482.

40. Venn A, Yemaneberhan H, Lewis S, Parry E, Britton J: Proximity of the home to roads and the risk of wheeze in an Ethiopian population. Occup Environ Med 2005, 62:376-380.

41. South Africa: Electronic National Administration Traffic Information System (eNaTIS). [http://www.enatis.com]

42. International Study of Asthma and Allergies in Childhood (ISAAC) Phase II Modules. 1998 [http://isaac.auckland.ac.nz]

43. Masoli M, Fabian D, Holt S, Beasley R: Global Burden of Asthma Report. In Developed for the Global Initiative for Asthma (GINA). [http://www.ginasthma.org]

\section{doi:10.1186/1476-069X-13-32}

Cite this article as: Shirinde et al.: Association between wheeze and selected air pollution sources in an air pollution priority area in South Africa: a cross-sectional study. Environmental Health 2014 13:32.

\section{Submit your next manuscript to BioMed Central and take full advantage of:}

- Convenient online submission

- Thorough peer review

- No space constraints or color figure charges

- Immediate publication on acceptance

- Inclusion in PubMed, CAS, Scopus and Google Scholar

- Research which is freely available for redistribution 